\title{
Association between CYP2E1 polymorphisms and risk of gastric cancer: An updated meta-analysis of 32 case-control studies
}

\author{
MING-XING ZHANG ${ }^{1,2}$, KAI LIU $^{1}$, FU-GANG WANG $^{1}$, XIAO-WEN WEN $^{1}$ and XI-LIN SONG ${ }^{1}$ \\ ${ }^{1}$ Department of Gastrointestinal Surgery, Shandong Cancer Hospital and Institute, Jinan, Shandong 250117, P.R. China
}

Received April 1, 2015; Accepted March 3, 2016

DOI: $10.3892 / \mathrm{mco} .2016 .824$

\begin{abstract}
Previous studies suggested that RsaI/PstI and DraI polymorphisms on cytochrome P450 2E1 (CYP2E1) may be associated with susceptibility to gastric cancer (GC). However, this association remains ambiguous. A meta-analysis of previously published studies was performed in an attempt to elucidate this association. The odds ratio and $95 \%$ confidence interval were used to assess the strength of the association. In the overall analyses of $R s a \mathrm{I} / P s t \mathrm{I}$ and $D r a \mathrm{I}$, no association was identified. In the subgroup analyses, $R s a \mathrm{I} / P s t \mathrm{I}$ was identified to increase the risk of GC in the smoking population. In addition, in the previous studies of interactions with other genes, RsaI/Pst $\mathrm{I}$ was revealed to be associated with increased GC risks when glutathione S-transferase- $\mu-1$ or glutathione S-transferase $\theta-1$ was null or DraI was homozygous wild-type. However, these stratified analyses were lacking credibility due to the limitation of correlational study numbers. In conclusion, CYP2E1 polymorphisms revealed no association with the risk of GC.
\end{abstract}

\section{Introduction}

For the past few years, the worldwide incidence of gastric cancer (GC) has decreased (1); however, GC remains the second leading cause of cancer-associated mortality worldwide (2). The incidence and mortality rate is rising in Eastern Asia (1,2), particularly in China (3). The growth of GC incidences is hypothesized to be caused by the interplay of environmental and genetic factors, which varies between area, gender, age and habitual behaviors (4-8). Specific variant alleles may modify the effects of environmental exposures and the gene-environment interactions may partly affect GC

Correspondence to: Professor Xi-Lin Song, Department of Gastrointestinal Surgery, Shandong Cancer Hospital and Institute, 440 Ji-Yan Road, Jinan, Shandong 250117, P.R. China

E-mail: songxilin11@hotmail.com

Present address: ${ }^{2}$ Department of Gastrointestinal Surgery, Liaocheng People's Hospital, Liaocheng, Shandong 252000, P.R. China

Key words: cytochrome P450 2E1, RsaI/PstI, DraI, gastric cancer, polymorphism, meta-analysis incidence (5). In the last decade, more and more previous studies have focused on the association between polymorphisms and $\mathrm{GC}$, however, only a few revealed an association with $\mathrm{GC}(4,7)$.

As an important metabolic enzyme, cytochrome P450 2E1 (CYP2E1) is critical in the metabolism of nitrosamines, benzene and vinyl chloride in the human body (9-11). Nitrosamine is considered as a pathogenic factor of GC (12); therefore, it is assumed that the variant alleles in CYP2E1 may affect the incidence of GC (13).

RsaI/PstI and DraI polymorphisms are regarded as the most frequent and powerful polymorphisms in CYP2E1 (14). RsaI/PstI polymorphisms, which are in complete linkage disequilibrium in the 5'-flanking promoter region of CYP2E1, are associated with higher transcription and increased enzyme activity (15). The DraI polymorphisms, however, are considered only to enhance transcription (14). The variant alleles in $R s a \mathrm{I} / P s t \mathrm{I}$ polymorphisms cause three genotypes, termed wild-type homozygous (C1C1), heterozygous (C1C2) and variant homozygous (C2C2) $(15,16)$. DraI polymorphisms are divided into wild-type homozygous (DD), heterozygous (CD) and variant homozygous (CC) genotypes (17).

Studies concerning the association of RsaI/Pst I polymorphisms and GC susceptibility have been performed in numerous previous studies, however, the results remain uncertain and controversial (18-45). However, investigations regarding DraI polymorphisms have rarely been performed. In the present study, 32 case-control studies (18-45) of 4,953 cases and 6,626 controls were screened from published papers between January 1995 and October 2014. These previous studies were used to calculate pooled statistics by meta-analysis, aiming to clarify the relevance of CYP2E1 polymorphisms and GC risk.

\section{Materials and methods}

Identification of previous studies. Data screening was performed in PubMed (http://www.ncbi.nlm.nih.gov/pubmed) and China National Knowledge Infrastructure database (http://oversea. cnki.net/kns55/default.aspx) between January 1995 and October 2014, without language limitation. The key words used for screening were 'CYP2E1', 'Cytochrome P450 2El', 'polymorphism', 'gastric', 'neoplasm', 'cancer' and 'variation'. The titles and abstracts of each paper were browsed for preliminary screening. The references of retrieved papers were also examined to search for additional relevant studies. 
Inclusion and exclusion criteria. The previous studies were selected using the following inclusion criteria: i) Case-control studies; ii) studies focusing on the relevance between CYP2E1 RsaI/PstI or DraI polymorphisms and GC susceptibility; iii) studies where detailed genotype frequencies were provided. Previous studies lacking Hardy-Weinberg equilibrium (HWE) were excluded. The titles and abstracts were reviewed for selection and the full-text papers were intensively read to confirm eligibility. Two reviewers were required to screen the studies independently, according to the criteria, and a third was involved in discussing any disagreement occurring between the previous two reviewers.

Data extraction. A form was designed to gather the following information: First author, year, country, ethnicity, genotyping method, source of control, numbers of different genotypes in cases/controls and HWE. The authors of the previous studies were contacted to confirm dubious information.

Statistical analysis. The meta-analysis focused on the associations between the CYP2E1 polymorphisms (RsaI/PstI and DraI) and GC susceptibility. The pooled odds ratios (ORs) were used to explain the correlation. In the previous studies of $R s a \mathrm{I} / P s t \mathrm{I}$ polymorphisms, ORs and their $95 \%$ confidence intervals (CIs) were calculated for the dominant model $(\mathrm{C} 1 \mathrm{C} 2+\mathrm{C} 2 \mathrm{C} 2$ vs. $\mathrm{C} 1 \mathrm{C} 1)$ and allele frequency $\mathrm{C} 2$, vs. C1. An OR and 95\% CI $<1$ indicated a significant difference between the cases and controls. In the subgroup analysis, the previous studies were grouped according to ethnicity, source of control, smoking and drinking status, and histology type. The ORs and 95\% CIs of each group were also calculated to assess the influence of these factors on the association. In the previous studies of $\mathrm{DraI}$ polymorphisms, the ORs and 95\% CIs were estimated for the dominant model (CD + CC vs. DD) and allele frequency (C vs. D).

In the meta-analysis, the $\mathrm{I}^{2}$ value was used to confirm heterogeneity (46), with values $<25,25-50$ and $>50 \%$ indicating low, moderate and high heterogeneity, respectively. A $\chi^{2}$-based $\mathrm{Q}$ test was also used for the heterogeneity test $\left(\mathrm{P}_{\mathrm{h}}\right)$, together with the random-effect model, in order to obtain a relatively conservative outcome (47). The significance of the pooled ORs and their 95\% CIs were determined using the $\mathrm{Z}$ test. A Pearson's $\chi^{2}$ test was used for assessing the HWE.

In order to elucidate the influence of each previous study included, influence analysis was performed by excluding each study in turn and analyzing the homogeneity and effect size for the remaining studies. Publication bias was assessed using Begg and Mazumdar's adjusted rank correlation test (48) and the Egger regression asymmetry test (49). Funnel plots were also used to illustrate the publication bias (50). All statistical calculations were performed using STATA 12.0 software (StataCorp LP, College Station, TX, USA).

\section{Results}

Searching results and characteristics of the previous studies included in the meta-analysis. The flow diagram of the study selection process is shown in Fig. 1. A total of 81 previous studies were identified in the database search, among which three studies were duplicated. A further 35 previous studies

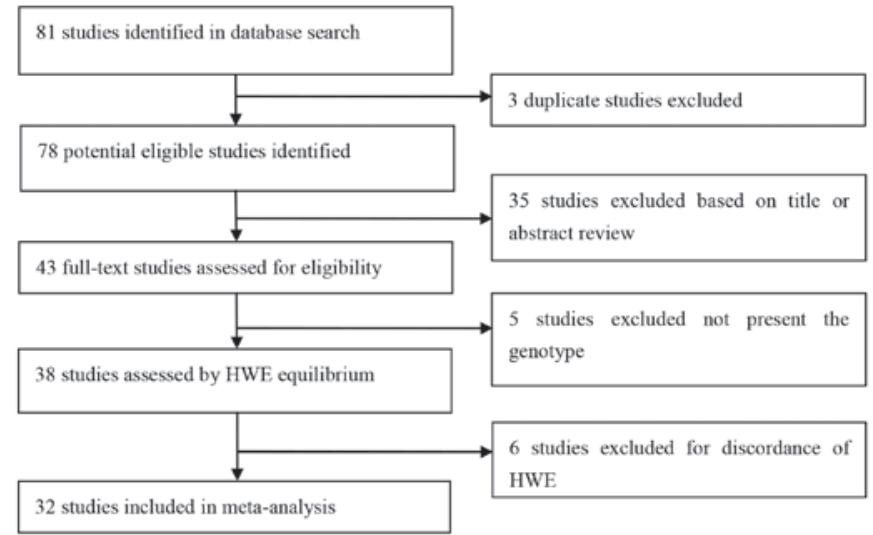

Figure 1. Flow diagram of included and excluded studies. HWE, Hardy-Weinberg equilibrium.

were excluded as a result of inconformity of case-control studies or irrelevance with the RsaI/PstI and DraI polymorphisms. The remaining 43 previous studies were read in full, among which five studies without detailed genotype frequencies were excluded. Following the exclusion of six previous studies for discordance of HWE, 32 previous studies were included in the meta-analysis (18-45). Of these, 26 were associated with $R s a \mathrm{I} / P s t \mathrm{I}$ polymorphisms, while the remaining six $(20,24,27,33,35,43)$ were investigating DraI polymorphisms. Details of these previous studies are shown in Table I.

These previous studies were subgrouped according to ethnicity, source of control, smoking and drinking status, and histology type. Stratified analysis was performed in these subgroups. Previous studies concerning the interactions between RsaI/Pst I and glutathione S-transferase- $\mu-1$ (GSTM1) (36), glutathione S-transferase $\theta-1$ (GSTT1) (40) or DraI $(27,35)$ were listed and analyzed in order to identify more factors, which may influence the risk of GC (Table II).

Meta-analysis results. In the overall analysis of RsaI/Pst polymorphisms, the ORs and $95 \%$ CIs were 0.96 (0.82 and 1.12) in the dominant model $(\mathrm{C} 1 \mathrm{C} 2+\mathrm{C} 2 \mathrm{C} 2$ vs. C1C1) and 1.02 (0.86 and 1.19) in gene frequency (C2 vs. C1; Table III).

The subgroup analyses of the clinical characteristics are shown in Table III. In the source of control subgroups, no significant differences were observed either in population-based studies or hospital-based studies. As for ethnicity, no significant differences were observed in any of the three subgroups (Fig. 2). In the smoking status subgroup, a significantly increased risk was observed in the smoking group $[\mathrm{C} 1 \mathrm{C} 2 / \mathrm{C} 2 \mathrm{C} 2$ vs. $\mathrm{C} 1 \mathrm{C} 1=1.56$ (1.14 and 2.15), as shown in Fig. 3], while the non-smoking group revealed no significant difference. Subgroups of drinking status revealed no association with GC risk. In the previous studies, which assessed the interactions of different genes, RsaI/Pst I was demonstrated to increase GC risks when GSTM1 was null [2.60 (1.13 and 5.99)]. A significantly increased risk was also observed in the previous studies investigating the interaction between RsaI/PstI and GSTT1. In the GSTT1 null group, a significant difference was observed between increased risk of GC and RsaI/PstI [0.22 (0.09 and 0.54)]. 
Table I. Characteristics of previous studies in the meta-analysis.

\begin{tabular}{|c|c|c|c|c|c|c|c|c|c|c|c|c|}
\hline \multirow[b]{2}{*}{ Authors (year) } & \multirow[b]{2}{*}{ Country } & \multirow{2}{*}{ Ethnicity } & \multirow{2}{*}{$\begin{array}{l}\text { Genotyping } \\
\text { method }\end{array}$} & \multirow[b]{2}{*}{ Source } & \multicolumn{3}{|c|}{ Cases } & \multicolumn{3}{|c|}{ Control } & & \multirow[b]{2}{*}{ Refs. } \\
\hline & & & & & $\mathrm{C} 1 \mathrm{C} 1$ & $\mathrm{C} 1 \mathrm{C} 2$ & $\mathrm{C} 2 \mathrm{C} 2$ & $\mathrm{C} 1 \mathrm{C} 1$ & $\mathrm{C} 1 \mathrm{C} 2$ & $\mathrm{C} 2 \mathrm{C} 2$ & HWE & \\
\hline \multicolumn{13}{|l|}{ Ras $\mathrm{I} / P s t \mathrm{I}$} \\
\hline Ghoshal (2014) & India & Asian & PCR-RFLP & $\mathrm{PB}$ & 40 & 45 & 3 & 103 & 58 & 9 & Y & (25) \\
\hline Yan (2013) & China & Asian & PCR-RFLP & HB & 77 & 39 & 4 & 79 & 36 & 5 & $\mathrm{Y}$ & $(42)$ \\
\hline Feng (2012) & China & Asian & PCR-RFLP & HB & 348 & 128 & 34 & 374 & 119 & 17 & $\mathrm{Y}$ & (27) \\
\hline Malik et al (2009) & India & Asian & PCR-RFLP & $\mathrm{HB}$ & 88 & 20 & 0 & 177 & 17 & 1 & $\mathrm{Y}$ & (32) \\
\hline Agudo et al (2006) & Britain & Caucasian & PCR-RFLP & PB & 226 & 13 & 0 & 880 & 39 & 1 & $\mathrm{Y}$ & (18) \\
\hline Colombo et al (2004) & Brazil & Mixed & PCR-RFLP & $\mathrm{HB}$ & 89 & 11 & 0 & 134 & 16 & 0 & $\mathrm{Y}$ & (23) \\
\hline Zhou et al (2003) & China & Asian & PCR-RFLP & PB & 85 & 45 & 15 & 140 & 75 & 14 & $\mathrm{Y}$ & (45) \\
\hline Park et al (2003) & Korea & Asian & PCR-RFLP & PB & 80 & 33 & 7 & 94 & 48 & 3 & $\mathrm{Y}$ & (35) \\
\hline Wu et al (2002) & China & Asian & PCR-RFLP & HB & 215 & 108 & 33 & 199 & 70 & 9 & $\mathrm{Y}$ & (33) \\
\hline Tsukino et al (2002) & Japan & Asian & PCR-RFLP & $\mathrm{HB}$ & 71 & 42 & 7 & 88 & 58 & 12 & $\mathrm{Y}$ & (37) \\
\hline Cai et al (2001) & China & Asian & PCR-RFLP & $\mathrm{HB}$ & 58 & 27 & 6 & 71 & 22 & 1 & $\mathrm{Y}$ & (21) \\
\hline Qian et al (2001) & China & Asian & PCR-RFLP & $\mathrm{PB}$ & 88 & 47 & 7 & 88 & 68 & 8 & $\mathrm{Y}$ & (39) \\
\hline Kato et al (1995) & Japan & Asian & PCR-RFLP & $\mathrm{HB}$ & 90 & 54 & 6 & 120 & 69 & 14 & $\mathrm{Y}$ & (28) \\
\hline González et al (2004) & Costa Rica & Asian & PCR-RFLP & HB & 20 & 11 & 0 & 31 & 15 & 5 & $\mathrm{Y}$ & (19) \\
\hline Boccia et al (2007) & Italy & Caucasian & PCR-RFLP & HB & 102 & 5 & - & 234 & 20 & - & $\mathrm{Y}$ & (20) \\
\hline Gao et al (2002) & China & Asian & PCR-RFLP & PB & 58 & 31 & 9 & 121 & 62 & 13 & $\mathrm{Y}$ & $(22)$ \\
\hline Nan et al (2005) & Korea & Asian & PCR-RFLP & $\mathrm{HB}$ & 69 & 39 & - & 129 & 88 & - & $\mathrm{Y}$ & (26) \\
\hline Kato et al (2011) & Japan & Asian & PCR-RFLP & $\mathrm{HB}$ & 280 & 186 & - & 340 & 213 & - & $\mathrm{Y}$ & (30) \\
\hline Kato et al (1996) & Japan & Asian & PCR-RFLP & $\mathrm{HB}$ & 55 & 29 & - & 87 & 61 & - & $\mathrm{Y}$ & (29) \\
\hline Malakar et al (2014) & India & Asian & PCR-RFLP & PB & 93 & 11 & 1 & 182 & 28 & 0 & $\mathrm{Y}$ & (31) \\
\hline Nishimoto et al (2000) & Japan & Asian & PCR-RFLP & $\mathrm{HB}$ & 31 & 27 & 1 & 69 & 58 & 6 & $\mathrm{Y}$ & (34) \\
\hline Suzuki et al (2004) & Japan & Asian & PCR-RFLP & $\mathrm{HB}$ & 107 & 38 & - & 112 & 65 & - & $\mathrm{Y}$ & (36) \\
\hline $\mathrm{Li}$ and $\mathrm{Xu}(2007)$ & China & Asian & PCR-RFLP & $\mathrm{HB}$ & 25 & 10 & 6 & 17 & 16 & 8 & $\mathrm{Y}$ & (38) \\
\hline Qian et al (2003) & China & Asian & PCR-RFLP & $\mathrm{PB}$ & 64 & 22 & 4 & 47 & 39 & 4 & $\mathrm{Y}$ & $(40)$ \\
\hline Wang et al (2005) & China & Asian & PCR-RFLP & $\mathrm{HB}$ & 33 & 14 & 1 & 22 & 23 & 3 & $\mathrm{Y}$ & (41) \\
\hline Ye (2002) & China & Asian & PCR-RFLP & $\mathrm{HB}$ & 39 & 13 & 4 & 26 & 24 & 6 & $\mathrm{Y}$ & (44) \\
\hline \multicolumn{13}{|l|}{ DraI } \\
\hline Yan (2013) & China & Asian & PCR-RFLP & $\mathrm{HB}$ & 70 & 42 & 8 & 70 & 46 & 4 & $\mathrm{Y}$ & (42) \\
\hline Feng et al (2012) & China & Asian & PCR-RFLP & $\mathrm{HB}$ & 334 & 131 & 45 & 318 & 160 & 32 & $\mathrm{Y}$ & (27) \\
\hline Wu et al (2002) & China & Asian & PCR-RFLP & HB & 195 & 120 & 41 & 158 & 100 & 20 & $\mathrm{Y}$ & (33) \\
\hline Park et al (2003) & Korea & Asian & PCR-RFLP & $\mathrm{PB}$ & 78 & 35 & 7 & 85 & 45 & 8 & $\mathrm{Y}$ & (35) \\
\hline Boccia et al (2007) & Italy & Caucasian & PCR-RFLP & $\mathrm{HB}$ & 92 & 15 & - & 227 & 27 & - & $\mathrm{Y}$ & (20) \\
\hline Darazy et al (2011) & Lebanon & Asian & PCR-RFLP & $\mathrm{PB}$ & 12 & 1 & 0 & 66 & 4 & 0 & $\mathrm{Y}$ & (24) \\
\hline
\end{tabular}

HWE, Hardy Weinberg equilibrium; PCR-RFLP, polymerase chain reaction-restriction fragment length polymorphism; PB, population-based; $\mathrm{HB}$, hospital-based; $\mathrm{C} 1 \mathrm{C} 1$, wild-type homozygous; $\mathrm{C} 1 \mathrm{C} 2$, heterozygous; $\mathrm{C} 2 \mathrm{C} 2$, variant homozygous.

In the meta-analysis of DraI polymorphisms, no significant risk of GC susceptibility was observed either in the dominant model (CD + CC vs. DD) or allele frequency (C vs. D). However, the interaction analysis of RsaI/PstI and DraI on CYP2E1 revealed that $R s a \mathrm{I} / P s t \mathrm{I}$ significantly increased the risk of GC when DraI was wild-type (DD) [1.55 (1.13 and 2.14)].

Heterogeneity between the previous studies. Heterogeneities of each comparison are shown in Table III. The results revealed that $\mathrm{I}^{2}=61.4 \%$ and $\mathrm{P}_{\mathrm{h}}<0.001$. Compared with the overall analysis of RsaI/PstI polymorphisms, heterogeneities decreased in several subgroups (population-based controls group: $\mathrm{I}^{2}=35.3 \%$ and $\mathrm{P}_{\mathrm{h}}=0.147$; Caucasian group: $\mathrm{I}^{2}=41.1 \%$ and $\mathrm{P}_{\mathrm{h}}=0.192$ ).
In previous DraI polymorphism studies, the heterogeneity P-values were markedly higher compared with the critical value $(\mathrm{P}=0.01)$, noting that heterogeneities in the group of DraI polymorphisms were very little.

Sensitivity analysis. Influence analysis was performed by excluding studies one-by-one and analyzing the homogeneity and effect size for all of the remaining studies, aiming at examining the stability of the analysis. The results revealed that no individual study affected the pooled ORs significantly, in either the RsaI/PstI or DraI studies, confirming the stability of the analysis. This was associated with the high quality of the previous studies included. 
Table II. Distribution of CYP2E1 RsaI/PstI and influential factors.

\begin{tabular}{|c|c|c|c|c|c|}
\hline \multirow{3}{*}{$\begin{array}{l}\text { Influential factors } \\
\text { (Exposure + vs. exposure -) }\end{array}$} & \multicolumn{4}{|c|}{ No. (cases/controls) of CYP2E1 Rsal/Pstl polymorphism } & \multirow[b]{3}{*}{ Refs } \\
\hline & \multicolumn{2}{|c|}{$\mathrm{C} 1 \mathrm{C} 1$} & \multicolumn{2}{|c|}{$\mathrm{C} 1 \mathrm{C} 2+\mathrm{C} 2 \mathrm{C} 2$} & \\
\hline & Exposure + & Exposure - & Exposure + & Exposure - & \\
\hline \multicolumn{6}{|l|}{ Smoking (ever vs. never) } \\
\hline Cai et al (2001) & $37 / 23$ & $21 / 48$ & $23 / 11$ & $10 / 12$ & $(21)$ \\
\hline Agudo et al (2006) & $151 / 503$ & $79 / 403$ & $9 / 18$ & $4 / 22$ & $(18)$ \\
\hline Boccia et al (2007) & $49 / 99$ & $53 / 135$ & $1 / 9$ & $4 / 11$ & $(20)$ \\
\hline Gao et al (2002) & $41 / 75$ & $17 / 44$ & $32 / 25$ & $8 / 37$ & $(22)$ \\
\hline Malakar et al (2014) & $73 / 105$ & $20 / 77$ & $20 / 11$ & $8 / 1$ & $(31)$ \\
\hline Zhou et al (2003) & $66 / 83$ & $19 / 54$ & $47 / 42$ & $12 / 45$ & $(45)$ \\
\hline \multicolumn{6}{|l|}{ Drinking (ever vs. never) } \\
\hline Zhou et al (2003) & $33 / 33$ & $49 / 107$ & $23 / 22$ & $36 / 66$ & (45) \\
\hline Suzuki et al (2004) & $48 / 32$ & $51 / 51$ & $17 / 13$ & $20 / 34$ & (36) \\
\hline Malakar et al (2014) & $43 / 73$ & $51 / 109$ & $4 / 16$ & $8 / 12$ & $(31)$ \\
\hline Gao et al (2002) & $9 / 13$ & $49 / 108$ & $5 / 9$ & $35 / 66$ & $(22)$ \\
\hline Cai et al (2001) & $32 / 20$ & $25 / 51$ & $19 / 8$ & $14 / 15$ & $(21)$ \\
\hline Boccia et al (2007) & $68 / 123$ & $32 / 111$ & $5 / 10$ & $0 / 10$ & (20) \\
\hline \multicolumn{6}{|c|}{ Histology type (intestinal vs. diffuse) } \\
\hline Ghoshal et al (2014) & $27 / 103$ & $8 / 103$ & $23 / 67$ & $20 / 67$ & $(25)$ \\
\hline Kato et al (1996) & $27 / 87$ & $28 / 87$ & $17 / 61$ & $12 / 61$ & (29) \\
\hline Wu et al (2002) & $98 / 199$ & $99 / 199$ & $49 / 79$ & $46 / 79$ & $(33)$ \\
\hline Nishimoto et al (2000) & $17 / 69$ & $8 / 69$ & $6 / 64$ & $3 / 19$ & (34) \\
\hline Suzuki et al (2004) & $52 / 112$ & $55 / 112$ & $15 / 65$ & $23 / 65$ & (36) \\
\hline \multicolumn{6}{|l|}{ GSTM1 (present vs. null) } \\
\hline Suzuki et al (2004) & $67 / 22$ & $45 / 30$ & $26 / 5$ & $39 / 10$ & (36) \\
\hline \multicolumn{6}{|l|}{ GSTT1 (present vs. null) } \\
\hline Zhou et al (2003) & $22 / 30$ & $42 / 17$ & $14 / 21$ & $12 / 22$ & $(45)$ \\
\hline \multicolumn{6}{|c|}{ CYP2E1 DraI (DD vs. CD + CC) } \\
\hline Park et al (2003) & $71 / 79$ & $9 / 13$ & $7 / 6$ & $33 / 40$ & $(35)$ \\
\hline Feng et al (2012) & $212 / 233$ & $136 / 141$ & $122 / 85$ & $40 / 51$ & $(27$ \\
\hline
\end{tabular}

CYP2E1, cytochrome P450 2E1; GSTM1, glutathione S-transferase- $\mu$-1; GSTT1, glutathione S-transferase $\theta$-1; C1C1, wild-type homozygous; $\mathrm{C} 1 \mathrm{C} 2$, heterozygous; $\mathrm{C} 2 \mathrm{C} 2$, variant homozygous; $\mathrm{DD}$, wild-type homozygous; $\mathrm{CD}$, heterozygous; $\mathrm{CC}$, variant homozygous.

Publication bias. Begg and Mazumdar's adjusted rank correlation test and the Egger regression asymmetry test were each used to examine the publication bias, as well as funnel plots. The results revealed that no publication bias was observed in RsaI/PstI (Fig. 4) and DraI studies. Publication bias occurred in the studies of RsaI/Pst [Egger's test: $\mathrm{P}=0.033$ in the dominant model $(\mathrm{C} 1 \mathrm{C} 2+\mathrm{C} 2 \mathrm{C} 2$, vs. $\mathrm{C} 1 \mathrm{C} 1)]$, while no publication bias was observed in the DraI studies.

\section{Discussion}

For previous studies of $R s a \mathrm{I} / P s t \mathrm{I}$ polymorphisms, the overall analysis revealed no association between mutant $\mathrm{C} 2$ and $\mathrm{GC}$ risk. However, in the subgroup analysis, mutant $\mathrm{C} 2$ in $R s a \mathrm{I} / P s t \mathrm{I}$ significantly increased GC risk in the smoking population and GSTM1- or GSTT1-null populations. In the DraI polymorphism studies, variant allele $\mathrm{C}$ revealed no association with GC risk. In the interaction analysis, $\mathrm{C} 2$ in $R s a \mathrm{I} / P s t \mathrm{I}$ was revealed to increase GC risk when the DraI was not mutated.

The present study obtained two meta-analyses focusing on the association between RsaI/Pst I polymorphisms and GC susceptibility $(20,51)$. It was demonstrated that RsaI/PstI polymorphisms increased GC risk in the smoking population; however, no focus on the DraI polymorphisms or the interactions between two polymorphisms was provided. Therefore, the updated meta-analysis included 32 previous studies, in which 26 studies were on RsaI/Pst I and the remaining six studies were on DraI. In our meta-analysis, more subgroups were made due to their potential influence on GC susceptibility. Furthermore, the present study demonstrated the interaction analysis between different gene polymorphisms. Previous studies on these interaction analyses may be insufficient; however, the results obtained may provide a guidance of which type of studies are required in the future. 
Table III. Stratified analyses of polymorphisms in the CYP2E1 gene with gastric cancer risk.

\begin{tabular}{|c|c|c|c|c|c|c|c|c|c|}
\hline \multirow[b]{2}{*}{ Rsal/Pstl } & \multirow[b]{2}{*}{$\begin{array}{c}\text { No. } \\
\text { (cases/controls) }\end{array}$} & \multicolumn{4}{|c|}{$\mathrm{C} 2$ vs. $\mathrm{C} 1$} & \multicolumn{4}{|c|}{$\mathrm{C} 1 \mathrm{C} 2 / \mathrm{C} 2 \mathrm{C} 2$ vs. $\mathrm{C} 1 \mathrm{C} 1$} \\
\hline & & $\begin{array}{c}\text { OR } \\
(95 \% \mathrm{CI})\end{array}$ & P-value & $\mathrm{P}_{\mathrm{h}}$ & $\begin{array}{l}\mathrm{I}^{2} \\
(\%)\end{array}$ & $\begin{array}{c}\text { OR } \\
(95 \% \mathrm{CI})\end{array}$ & P-value & $\mathrm{P}_{\mathrm{h}}$ & $\begin{array}{l}\mathrm{I}^{2} \\
(\%)\end{array}$ \\
\hline Overall & $3,727 / 5,510$ & $1.02(0.86,1.19)$ & 0.850 & $<0.001$ & 61.4 & $0.96(0.82,1.12)$ & 0.574 & $<0.001$ & 56.2 \\
\hline \multicolumn{10}{|l|}{ Source of controls } \\
\hline $\mathrm{PB}$ & $1,027 / 2,124$ & $1.02(0.84,1.25)$ & 0.811 & 0.147 & 35.3 & $0.96(0.73,1.28)$ & 0.828 & 0.032 & 54.4 \\
\hline $\mathrm{HB}$ & $2,700 / 3,386$ & $1.00(0.79,1.27)$ & 0.993 & $<0.001$ & 70.2 & $0.94(0.78,1.15)$ & 0.583 & 0.001 & 59.0 \\
\hline \multicolumn{10}{|l|}{ Ethnicities } \\
\hline Asian & $3,281 / 4,186$ & $1.01(0.85,1.20)$ & 0.954 & $<0.001$ & 65.1 & $0.95(0.81,1.12)$ & 0.562 & $<0.001$ & 60.3 \\
\hline Caucasian & $346 / 1,174$ & $1.23(0.65,2.31)$ & 0.526 & - & - & $0.94(0.44,2.00)$ & 0.872 & 0.192 & 41.1 \\
\hline Mixed & $100 / 150$ & $1.03(0.47,2.27)$ & 0.936 & - & - & $1.04(0.46,2.33)$ & 0.934 & - & - \\
\hline \multicolumn{10}{|l|}{ Smoking status } \\
\hline Ever smoking & $549 / 1,014$ & - & - & - & - & $1.56(1.14,2.15)$ & 0.006 & 0.376 & 6.3 \\
\hline Never smoking & $255 / 889$ & - & - & - & - & $1.23(0.59,2.60)$ & 0.571 & 0.018 & 63.3 \\
\hline \multicolumn{10}{|l|}{ Drinking status } \\
\hline Ever drinking & $305 / 372$ & - & - & - & - & $0.91(0.61,1.37)$ & 0.676 & 0.752 & 0.0 \\
\hline Never drinking & $371 / 740$ & - & - & - & - & $1.08(0.75,1.54)$ & 0.663 & 0.238 & 26.2 \\
\hline \multicolumn{10}{|l|}{ Histology type } \\
\hline Intestinal & $331 / 906$ & - & - & - & - & $0.84(0.54,1.32)$ & 0.456 & 0.045 & 58.9 \\
\hline Diffuse & $315 / 906$ & - & - & - & - & $1.05(0.71,1.58)$ & 0.798 & 0.131 & 43.6 \\
\hline \multicolumn{10}{|l|}{ GSTM1 status } \\
\hline Present & $93 / 27$ & - & - & - & - & $1.71(0.59,4.99)$ & 0.328 & - & - \\
\hline Null & $84 / 40$ & - & - & - & - & $2.60(1.13,5.99)$ & 0.025 & - & - \\
\hline \multicolumn{10}{|l|}{ GSTT1 status } \\
\hline Present & $36 / 51$ & - & - & - & - & $0.91(0.38,2.17)$ & 0.830 & - & - \\
\hline Null & $54 / 39$ & - & - & - & - & $0.22(0.09,0.54)$ & 0.001 & - & - \\
\hline \multicolumn{10}{|l|}{ DraI status } \\
\hline $\mathrm{DD}$ & $412 / 403$ & - & - & - & - & $1.55(1.13,2.14)$ & 0.007 & 0.747 & 0.0 \\
\hline \multirow[t]{2}{*}{$\mathrm{CD}+\mathrm{CC}$} & $218 / 165$ & - & - & - & - & $0.88(0.57,1.34)$ & 0.544 & 0.487 & 0.0 \\
\hline & & \multicolumn{4}{|c|}{ C vs. D } & \multicolumn{4}{|c|}{$\mathrm{CD}+\mathrm{CC}$ vs. DD } \\
\hline $\operatorname{DraI}$ & $\begin{array}{c}\text { No. } \\
\text { (cases/controls) }\end{array}$ & $\begin{array}{c}\text { OR } \\
(95 \% \mathrm{CI})\end{array}$ & P-value & $\mathrm{P}_{\mathrm{h}}$ & $\begin{array}{l}\mathrm{I}^{2} \\
(\%)\end{array}$ & $\begin{array}{c}\text { OR } \\
(95 \% \mathrm{CI})\end{array}$ & P-value & $\mathrm{P}_{\mathrm{h}}$ & $\begin{array}{l}\mathrm{I}^{2} \\
(\%)\end{array}$ \\
\hline Overall & $1,226 / 1,116$ & $1.05(0.91,1.20)$ & 0.540 & 0.784 & 0.0 & $0.97(0.82,1.15)$ & 0.727 & 0.782 & 0.0 \\
\hline
\end{tabular}

CYP2E1, cytochrome P450 2E1; OR, odds ratio; CI, confidence interval; PB, population-based; HB, hospital-based; GSTM1, glutathione S-transferase- $\mu$-1; GSTT1, glutathione S-transferase $\theta-1$; DD, wild-type homozygous; CD, heterozygous; CC, variant homozygous.

In the 26 studies of RsaI/Pst I polymorphisms, no significant differences were observed in the homozygous dominant model $(\mathrm{C} 1 \mathrm{C} 2+\mathrm{C} 2 \mathrm{C} 2$ vs. $\mathrm{C} 1 \mathrm{C} 1)$ and in $\mathrm{C} 2$ vs. $\mathrm{C} 1$, indicating the lack of association between the RsaI/Pst $\mathrm{I}$ polymorphisms and the risk of GC.

In the subgroup analysis on source of controls, no statistically significant risks were observed in either groups with hospital-based controls or groups with population-based controls. Although hospital-based controls may not always be truly representative of the general population (52), differences were reflected between GC patients and those of healthy individuals. Population-based controls are an improved representation of the entire population gene frequency compared with hospital-based controls, and provide a good reflection of gene frequency differences between GC patients and the overall population. Therefore, more case-control studies based on population-based controls will be performed in the future.

As for the subgroup analysis of ethnicity, no statistically significant differences were observed among groups of Asians, Caucasian or mixed. Although no statistically significant differences appeared in the subgroups, heterogeneity of the genotype frequencies existed in different ethnic groups clinically. The variant alleles C2 and C frequencies in CYP2E1 harbored in 


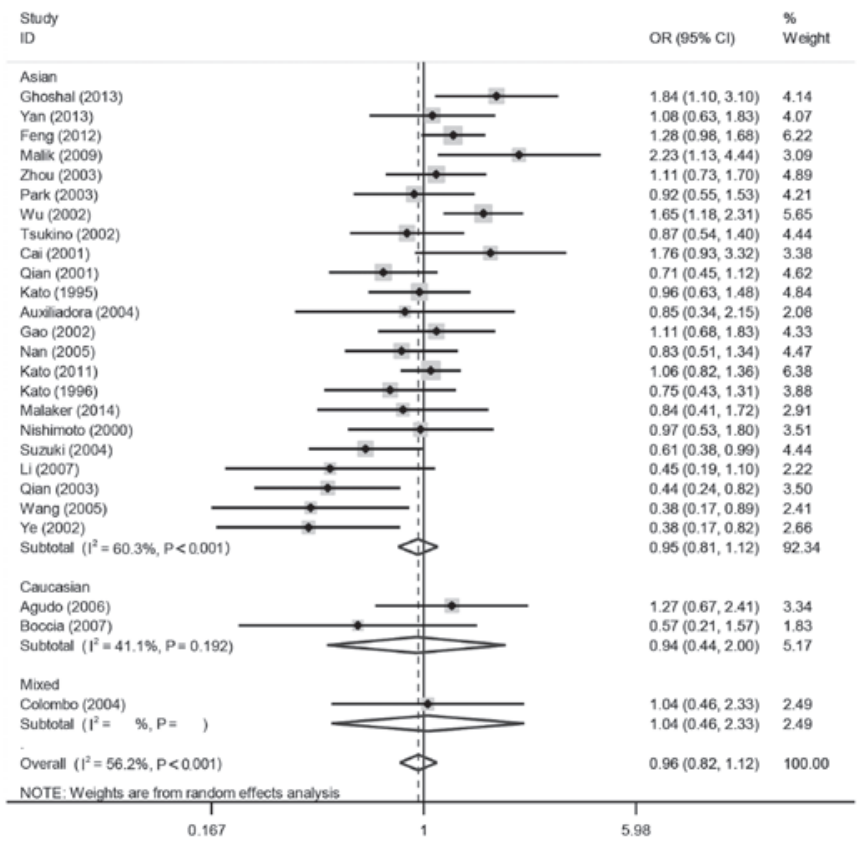

Figure 2. Forest plot of dominant comparison model (C1C2/C2C2 vs. C1C1) for subgroup comparison in $R s a \mathrm{I} / P s t \mathrm{I}$. OR, odds ratio; CI, confidence interval.

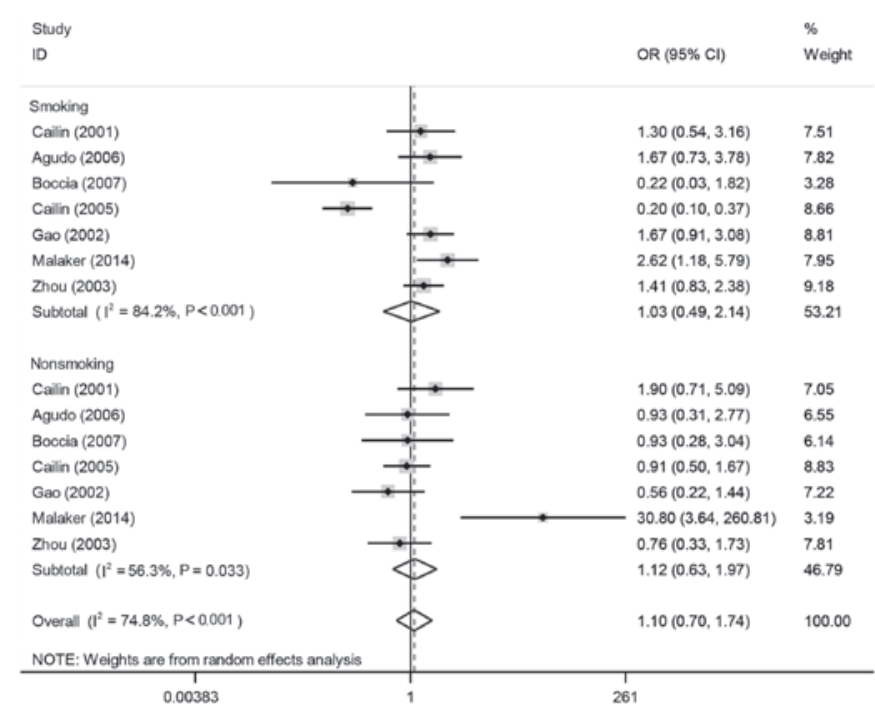

Figure 3. Forest plot of dominant comparison model for subgroup comparison (smoking status) in RsaI/PstI. OR, odds ratio; CI, confidence interval.

Asians are markedly higher compared with those in aCaucasians or African-Americans (53-55). Similar cases were observed in several other polymorphisms (56). It is hypothesized that various living environments and diverse genotypes lead to different degrees of cancer susceptibility (8). A lack of association between GC risks and RsaI/PstI in Caucasians and mixed populations may be attributed to insufficiency of studies included and more studies of Caucasians are required in the future.

In the smoking subgroup, mutant $\mathrm{C} 2$ was demonstrated to be associated with increased GC risk. A previous study (57) revealed that smoking is a risk of cancer. Tobacco smoke contains many carcinogens, including benzopyrene and nitrosamine. CYP2E1 is critical in the metabolism of nitrosamines,

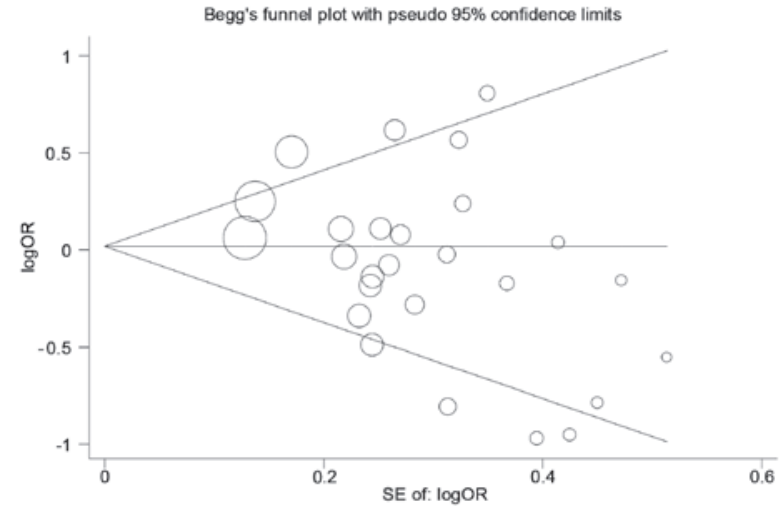

Figure 4. Funnel plot for publication bias in dominant model (C1C2/C2C2 vs. C1C1) in RsaI/PstI polymorphisms. (Begg's P-value $=0.108$, Egger's P-value $=0.033)$. OR, odds ratio; $\mathrm{SE}$, standard error.

benzene and vinyl chloride in the human body. Therefore, the interaction between smoking and CYP2E1 polymorphisms may magnify the GC incidence. Previous studies focusing on the interaction between smoking status and CYP2E1 were few, and more credible results depended on more studies being included (18,20-22,31,45).

In the drinking status subgroup, no significant association was observed between RsaI/PstI polymorphisms and GC risk. Alcohol can directly stimulate the gastric mucosa and damage gastric mucosal, making the gastric mucosal epithelium more susceptible to carcinogens (58). In addition, the stimulation of alcohol activated the function of CYP2E1 and in this resulted in an increased GC susceptibility with a synergistic effect. More studies involving an interaction between drinking and CYP2E1 polymorphisms may assist in obtaining a positive result.

According to the pathological type, GC can be divided into intestinal and diffuse types. Tumor cells in the intestinal type are normally confined to the lining of the stomach, while the diffuse type has a tendency to widely spread. The subgroup analysis may assist in understanding how differences in CYP2E1 affects the two types of GC. However, the result revealed no significant difference between the intestinal and diffuse groups.

Six previous DraI polymorphism studies (20,24,27,33,35,43), showed that no significant association was observed between DraI polymorphisms and GC risk. However, in consideration of the fact that only six studies were included in the research regarding DraI polymorphisms, the reliability of the results depended on more DraI studies being included. These results should be treated with caution, as more case-control tests are required to support the results.

Tumor incidence is often a combination of multiple factors. The interaction of multiple genes increases the impact on GC susceptibility compared with a single gene. Notably, negative association between a gene and cancer susceptibility does not mean that the gene has no impact on cancer risk. In the previous studies, which involved RsaI/PstI polymorphisms and other genes, it was revealed that the $R s a \mathrm{I} / P s t \mathrm{I}$ polymorphism significantly increases GC risk when GSTM1 or GSTT1 were in a null status. GSTT1 and GSTM1 convert carcinogens in the body into an inactive state, therefore, detoxifying them. However, when GSTT1 and GSTM1 are mutated into a null state, their 
detoxification functions are lost, which increases cancer susceptibility (59). Additionally, mutant genotype C2 in RsaI/PstI has a suppressive effect in this process and GC risk was increased by such an interaction theoretically. Statistically, no significant result was obtained. However, the results were based on limited research data and the credibility was questionable. Further studies are required to improve the result in the future.

The two polymorphisms on an identical gene may lead to a synergistic effect or antagonism. When analyzing the interaction of RsaI/Pst I and DraI polymorphisms, the mutant C2 in RsaI/PstI was revealed to increase GC risk when the DraI was without mutation (DD). This result may reveal that the two polymorphisms are working antagonistically. An RsaI/PstI mutation may increase cancer risks, while DraI functions with the opposite effect. Previous studies $(17,60)$ on DraI polymorphisms and cancer susceptibility have revealed that DraI was more likely to be a risk factor of cancer, which is contrary to our assumption. By contrast, limited data may bring the contingency and must be treated with caution.

The heterogeneities in the subgroups of Caucasians and population-based controls decreased compared with the overall analysis of the RsaI/PstI polymorphisms, meaning that the source of controls and ethnic groups are undoubtedly factors for the formation of heterogeneity.

Publication bias occurred in the studies of RsaI/Pst I, most probably due to several reasons: Previous studies with negative results are more difficult to publish compared with those with positive results; authors prefer to write articles with positive results as opposed to negative results. The existence of publication bias led to our cautious attitude to the positive results obtained in the present meta-analysis.

Certain limitations were observed in this meta-analysis. Firstly, only published results were included, which actually contributed to publication bias, causing the results to be treated with a conservative attitude. Secondly, several previous studies were excluded since they provided no detailed genotypic frequencies, therefore adding selection bias to a certain extent. Thirdly, more studies focusing on RsaI/Pst I and DraI polymorphisms in the same cases and controls were included; however, the authors provided no matched genotype frequencies of the two genetic loci, which resulted in exploring the interaction between them with limited data. Finally, the lack of the sample size influenced the credibility in several subgroup analyses and gene interaction studies. More studies focusing on large-scale samples with multi-variables are required in the future. In conclusion, a lack of association was observed between the risk of GC and CYP2E1 RsaI/PstI or DraI polymorphisms.

\section{Acknowledgements}

The authors would like to thank the Professors and members of the Department of Gastrointestinal Surgery, Shandong Cancer Hospital and Institute (Jinan, China) for their hard work.

\section{References}

1. Karimi P, Islami F, Anandasabapathy S, Freedman ND and Kamangar F: Gastric cancer: Descriptive epidemiology, risk factors, screening and prevention. Cancer Epidemiol Biomarkers Prev 23: 700-713, 2014.
2. Jemal A, Bray F, Center MM, Ferlay J, Ward E and Forman D: Global cancer statistics. CA Cancer J Clin 61: 69-90, 2011.

3. Yang L: Incidence and mortality of gastric cancer in China. World J Gastroenterol 12: 17-20, 2006.

4. Gianfagna F, De Feo E, van Duijn CM, Ricciardi G and Boccia S: A systematic review of meta-analyses on gene polymorphisms and gastric cancer risk. Curr Genomics 9: 361-374, 2008.

5. Hamilton JP and Meltzer SJ: A review of the genomics of gastric cancer. Clin Gastroenterol Hepatol 4: 416-425, 2006.

6. Milne AN, Carneiro F, O'Morain C and Offerhaus GJ: Nature meets nurture: Molecular genetics of gastric cancer. Hum Genet 126: 615-628, 2009.

7. Saeki N, Ono H, Sakamoto H and Yoshida T: Genetic factors related to gastric cancer susceptibility identified using a genome-wide association study. Cancer Sci 104: 1-8, 2013.

8. Yoshida T, Ono H, Kuchiba A, Saeki N and Sakamoto H: Genome-wide germline analyses on cancer susceptibility and GeMDBJ database: Gastric cancer as an example. Cancer Sci 101: 1582-1589, 2010.

9. Bellec G, Dréano Y, Lozach P, Ménez JF and Berthou F: Cytochrome P450 metabolic dealkylation of nine $\mathrm{N}$-nitrosodialkylamines by human liver microsomes. Carcinogenesis 17: 2029-2034, 1996.

10. Ingelman-Sundberg M, Ronis MJ, Lindros KO, Eliasson E and Zhukov A: Ethanol-inducible cytochrome P4502E1: Regulation, enzymology and molecular biology. Alcohol Alcohol Suppl 2: 131-139, 1994.

11. Raucy JL, Kraner JC and Lasker JM: Bioactivation of halogenated hydrocarbons by cytochrome P4502E1. Crit Rev Toxicol 23: 1-20, 1993.

12. La Vecchia C, D'Avanzo B, Airoldi L, Braga C and Decarli A: Nitrosamine intake and gastric cancer risk. Eur J Cancer Prev 4: 469-474, 1995.

13. Agundez JA: Cytochrome P450 gene polymorphism and cancer. Curr Drug Metab 5: 211-224, 2004.

14. Uematsu F, Ikawa S, Kikuchi H, et al: Restriction fragment length polymorphism of the human CYP2E1 (cytochrome P450IIE1) gene and susceptibility to lung cancer: Possible relevance to low smoking exposure. Pharmacogenetics 4: 58-63, 1994.

15. Hayashi S, Watanabe J and Kawajiri K: Genetic polymorphisms in the 5'-flanking region change transcriptional regulation of the human cytochrome P450IIE1 gene. J Biochem 110: 559-565, 1991.

16. Uchimoto T, Itoga S, Nezu M, Sunaga M, Tomonaga $T$ and Nomura F: Role of the genetic polymorphisms in the 5'-flanking region for transcriptional regulation of the human CYP2E1 gene. Alcohol Clin Exp Res 31 (Suppl 1): S36-S42, 2007.

17. Tang K, Li Y, Zhang Z, et al: The PstI/RsaI and DraI polymorphisms of CYP2E1 and head and neck cancer risk: A meta-analysis based on 21 case-control studies. BMC Cancer 10: 575, 2010.

18. Agudo A, Sala N, Pera G, et al: No association between polymorphisms in CYP2E1, GSTM1, NAT1, NAT2 and the risk of gastric adenocarcinoma in the European prospective investigation into cancer and nutrition. Cancer Epidemiol Biomarkers Prev 15: 1043-1045, 2006.

19. González A, Ramírez V, Cuenca P and Sierra R: Polymorphisms in detoxification genes CYP1A1, CYP2E1, GSTT1 and GSTM1 in gastric cancer susceptibility. Rev Biol Trop 52: 591-600, 2004 (In Spanish).

20. Boccia S, De Lauretis A, Gianfagna F, van Duijn CM and Ricciardi G: CYP2E1PstI/RsaI polymorphism and interaction with tobacco, alcohol and GSTs in gastric cancer susceptibility: A meta-analysis of the literature. Carcinogenesis 28: 101-106, 2007.

21. Cai L, Yu SZ and Zhan ZF: Cytochrome P450 2E1 genetic polymorphism and gastric cancer in Changle, Fujian Province. World J Gastroenterol 7: 792-795, 2001.

22. Gao C, Takezaki T, Wu J, et al: Interaction between cytochrome $\mathrm{P}-450$ 2E1 polymorphisms and environmental factors with risk of esophageal and stomach cancers in Chinese. Cancer Epidemiol Biomarkers Prev 11: 29-34, 2002.

23. Colombo J, Rossit AR, Caetano A, Borim AA, Wornrath D and Silva AE: GSTT1, GSTM1 and CYP2E1 genetic polymorphisms in gastric cancer and chronic gastritis in a Brazilian population. World J Gastroenterol 10: 1240-1245, 2004.

24. Darazy M, Balbaa M, Mugharbil A, et al: CYP1A1, CYP2E1, and GSTM1 gene polymorphisms and susceptibility to colorectal and gastric cancer among Lebanese. Genet Test Mol Biomarkers 15: 423-429, 2011.

25. Ghoshal U, Tripathi S, Kumar S, et al: Genetic polymorphism of cytochrome P450 (CYP) 1A1, CYP1A2 and CYP2E1 genes modulate susceptibility to gastric cancer in patients with Helicobacter pylori infection. Gastric Cancer 17: 226-234, 2014. 
26. Nan HM, Song YJ, Yun HY, Park JS and Kim H: Effects of dietary intake and genetic factors on hypermethylation of the hMLH1 gene promoter in gastric cancer. World J Gastroenterol 11: 3834-3841, 2005.

27. Feng J, Pan X, Yu J, et al: Functional PstI/RsaI polymorphism in CYP2E1 is associated with the development, progression and poor outcome of gastric cancer. PLoS One 7: e44478, 2012.

28. Kato S, Onda M, Matsukura N, et al: Cytochrome P4502E1 (CYP2E1) genetic polymorphism in a case-control study of gastric cancer and liver disease. Pharmacogenetics 5: S141-S144, 1995.

29. Kato S, Onda M, Matsukura N, et al: Genetic polymorphisms of the cancer related gene and Helicobacter pylori infection in Japanese gastric cancer patients. An age and gender matched case-control study. Cancer 77 (Suppl 8): S1654-S1661, 1996.

30. Kato S, Naito Z, Matsuda N, et al: Localization of cytochrome $\mathrm{P} 4502 \mathrm{E} 1$ enzyme in normal and cancerous gastric mucosa and association with its genetic polymorphism in unoperated and remnant stomach. J Nippon Med Sch 78: 224-234, 2011.

31. Malakar M, Devi KR, Phukan RK, et al: CYP2E1 genetic polymorphism with dietary, tobacco, alcohol habits, H. pylori infection status and susceptibility to stomach cancer in Mizoram, India. Asian Pac J Cancer Prev 15: 8815-8822, 2014.

32. Malik MA, Upadhyay R, Mittal RD, Zargar SA, Modi DR and Mittal B: Role of xenobiotic-metabolizing enzyme gene polymorphisms and interactions with environmental factors in susceptibility to gastric cancer in Kashmir Valley. J Gastrointest Cancer 40: 26-32, 2009

33. Wu MS, Chen CJ, Lin MT, et al: Genetic polymorphisms of cytochrome p450 2E1, glutathione S-transferase M1 and T1, and susceptibility to gastric carcinoma in Taiwan. Int J Colorectal Dis 17: 338-343, 2002.

34. Nishimoto IN, Hanaoka T, Sugimura H, et al: Cytochrome P450 2E1 polymorphism in gastric cancer in Brazil: Case control studies of Japanese Brazilians and non-Japanese Brazilians. Cancer Epidemiol Biomarkers Prev 9: 675-680, 2000

35. Park GT, Lee OY, Kwon SJ, et al: Analysis of CYP2E1 polymorphism for the determination of genetic susceptibility to gastric cancer in Koreans. J Gastroenterol Hepatol 18: 1257-1263, 2003.

36. Suzuki S, Muroishi Y, Nakanishi I and Oda Y: Relationship between genetic polymorphisms of drug-metabolizing enzymes (CYP1A1, CYP2E1, GSTM1 and NAT2), drinking habits, histological subtypes, and p53 gene point mutations in Japanese patients with gastric cancer. J Gastroenterol 39: 220-230, 2004.

37. Tsukino H, Kuroda Y, Qiu D, Nakao H, Imai H and Katoh T: Effects of cytochrome P450 (CYP) 2A6 gene deletion and CYP2E1 genotypes on gastric adenocarcinoma. Int J Cancer 100: 425-428, 2002

38. Li Z and Xu L: Relationship between cytochrome P450 2E1 gene polymorphism and gastric cancer susceptibility. J Pract Med: 3380-3381, 2007.

39. Qian Y, Xu Y, Shen H, Yu R, Tan Y, Zhou L and Niu J: Relationship between CYP2E1, GSTT1 genetic polymorphisms and susceptibility to gastric cancer. China's primary health care, 18-20, 2001.

40. Qian Y, Xu Y, Shen H, Zhou L, Yu R, Niu J and Tan Y: Relationship Between CYP2E1, GSTT1 Genetic Polymorphisms and Susceptibility to Gastric Cancer. Chin J Prev Control Chron Non Commun Dis: 107-109, 2003.

41. Wang Y, Jiang Y and Sun W: Effects of genetic polymorphism of cytochrome P4502E1 on susceptibility to gastric cancer. Chin J Publ Health: 664-665, 2005.
42. Yan S, Bai Z, Zhao J, Xie D and Wu J: Correlation between genetic polymorphisms of CYP2E1 RsaI and susceptibility of gastric cancer in Qinghai province. J Qinghai Med Coll 34: 7-14, 2013.

43. Su Y, Zhenzhong B, Jian-xin Z, et al: Correlation between genetic polymorphisms of CYP2E1 Dra I and susceptibility of gastric cancer in Qinghai province. China Oncol 23: 273-278, 2013.

44. Ye M, Liu J, Zhou X, and Deng C: Association between CYE2E1 genotype and genetic susceptibility of gastric cancer.J Fourth Mil Med Univ 2265-2267, 2002.

45. Zhou J, Gao C, Takezaki T, Li Z, Wu J, Ding J, Liu Y, Li S, $\mathrm{Hu} \mathrm{X}$, Kai $\mathrm{H}$ and Tajima K: Interaction between polymorphisms in CYP2E1 Rsa I genotypes and lifestyle with risk of stomach cancer. J Oncol 9: 285-288, 2003.

46. Higgins JP, Thompson SG, Deeks JJ and Altman DG: Measuring inconsistency in meta-analyses. BMJ 327: 557-560, 2003.

47. DerSimonian R and Laird N: Meta-analysis in clinical trials. Control Clin Trials 7: 177-188, 1986.

48. Begg CB and Mazumdar M: Operating characteristics of a rank correlation test for publication bias. Biometrics 50: 1088-1101, 1994.

49. Egger M, Davey Smith G, Schneider M and Minder C: Bias in meta-analysis detected by a simple, graphical test. BMJ 315 : 629-634, 1997.

50. Munafò MR, Clark TG and Flint J: Assessing publication bias in genetic association studies: Evidence from a recent meta-analysis. Psychiatry Res 129: 39-44, 2004.

51. Zhuo W, Zhang L, Wang Y, Ling J, Zhu B and Chen Z: CYP2E1 RsaI/PstI polymorphism and gastric cancer susceptibility: Meta-analyses based on 24 case-control studies. PLoS One 7: e48265, 2012

52. Ruano-Ravina A, Pérez-Ríos $M$ and Barros-Dios JM: Population-based versus hospital-based controls: Are they comparable? Gac Sanit 22: 609-613, 2008.

53. Garte S, Gaspari L, Alexandrie AK, et al: Metabolic gene polymorphism frequencies in control populations. Cancer Epidemiol Biomarkers Prev 10: 1239-1248, 2001.

54. Neafsey P, Ginsberg G, Hattis D, Johns DO, Guyton KZ and Sonawane B: Genetic polymorphism in CYP2E1: Population distribution of CYP2E1 activity. J Toxicol Environ Health B Crit Rev 12: 362-388, 2009.

55. Stephens EA, Taylor JA, Kaplan N, et al: Ethnic variation in the CYP2E1 gene: Polymorphism analysis of 695 African-Americans, European-Americans and Taiwanese. Pharmacogenetics 4: 185-192, 1994

56. Schmidt HM, Ha DM, Taylor EF, et al: Variation in human genetic polymorphisms, their association with Helicobacter pylori acquisition and gastric cancer in a multi-ethnic country. J Gastroenterol Hepatol 26: 1725-1732, 2011.

57. Benowitz NL, Peng M and Jacob P III: Effects of cigarette smoking and carbon monoxide on chlorzoxazone and caffeine metabolism. Clin Pharmacol Ther 74: 468-474, 2003.

58. Murata M, Takayama K, Choi BC and Pak AW: A nested case-control study on alcohol drinking, tobacco smoking, and cancer. Cancer Detect Prev 20: 557-565, 1996.

59. Masoudi M, Saadat I, Omidvari S and Saadat M: Genetic polymorphisms of GSTO2, GSTM1, and GSTT1 and risk of gastric cancer. Mol Biol Rep 36: 781-784, 2009.

60. Wu X, Amos CI, Kemp BL, et al: Cytochrome P450 2E1 DraI polymorphisms in lung cancer in minority populations. Cancer Epidemiol Biomarkers Prev 7: 13-18, 1998. 